\title{
A meta-analysis of the relationship between vaginal microecology, human papillomavirus infection and cervical intraepithelial neoplasia
}

\author{
Yuejuan Liang, Mengjie Chen, Lu Qin, Bing Wan and He Wang* (D)
}

\begin{abstract}
Microecology is an emerging discipline in recent years. The female reproductive tract is an important microecological region, and its microecological environment can directly affect women's cervical health. This metaanalysis aimed to analyze the effects of vaginal microecology on Human papillomavirus (HPV) infection and cervical intraepithelial neoplasia (CIN). PubMed and Web of Science were systematically searched for eligible publications from January 2000 to December 2017. Articles were selected on the basis of specific inclusion and exclusion criteria. The design and quality of all studies were evaluated using the Newcastle-Ottawa Scale (NOS). Odds ratios (ORs) with a $95 \%$ confidence interval $(95 \% \mathrm{Cl})$ were calculated. Thirteen eligible studies were selected to evaluate the association of vaginal microecology with HPV infection and CIN. The factors related to HPV infection were bacterial vaginosis (BV) (OR 2.57, 95\% Cl 1.78-3.71, $\mathrm{P}<0.05)$, Candida albicans (WC) (OR 0.63, 95\% Cl 0.49-0.82, $P<0.05)$, Chlamydia trachomatis (CT) (OR 3.16,95\% Cl 2.55-3.90, $P<0.05)$, and Ureaplasma urealyticum (UU) (OR $1.35,95 \% \mathrm{Cl}$ $1.20-1.51, P<0.05)$. BV was also related to CIN (OR 1.56, 95\% Cl 1.21-2.00, $P<0.05)$. This meta-analysis of available literature suggested an intimate association of vaginal microecology and HPV infection with CIN. BV, CT and UU were associated to increased HPV infection, WC was associated to decreased HPV infection, Lactobacillus is not associated to increased HPV infection, BV was associated to increased CIN development risk. Further large-scale studies are needed to confirm our findings.
\end{abstract}

Keywords: Vaginal microecology, HPV, CIN, Meta-analysis

\section{Background}

Cervical cancer is the second most common malignant tumor among women worldwide, second only to breast cancer [1]. Human papillomavirus (HPV) infection, especially high-risk human papilloma virus (HR-HPV) persistent infection, is a prerequisite for the development of cervical intraepithelial neoplasia (CIN) and cervical cancer [2]. The HPV infection rate of Chinese women was $15.71 \%$ in the previous years, and $84.6 \%$ of sexually active women were infected with HPV at least once in their lifetime, but few HPV infections persist and progress to cervical cancer [3]. Over 90\% HPV and CIN I, half of CIN II, and 30\% of CIN III can be self-contained [4-6]. In most of the cases, the HPV infection

* Correspondence: wanghe10430@126.com

The Department of Gynecological of Guangxi Medical University Cancer Hospital, Nanning City 530021, Guangxi Zhuang Autonomous Region, China is cleared by the immune system within 2 years [7]. The long-term retention of HPV that cannot be removed due to various factors such as cervicitis, multiple sexual partners, smoking, etc. causes the HPV viral load to remain at a high level in the body leading to cervical lesions, and are also closely related to the severity of cervical lesions $[8,9]$. Although HPV vaccines can significantly reduce HPV infection rates, most of developing countries are slow to introduce vaccinations [10]. Therefore, one of the primary means of preventing cervical lesions is to detect and block the sustained HR-HPV infection in a timely manner.

Identifying risk factors for the development of CIN and cervical cancer has been the objective of recent studies [11]. Normal vaginal microecology plays an indispensable role in the prevention of female genital tract infection and its alteration is inextricably linked to cervical lesions development

(c) The Author(s). 2019 Open Access This article is distributed under the terms of the Creative Commons Attribution 4.0 International License (http://creativecommons.org/licenses/by/4.0/), which permits unrestricted use, distribution, and 
[12]. The vagina is mainly composed of its anatomical structure, micro-ecological flora, local immunological and endocrine factors [13]. Although the normal microflora is the core focus of vaginal microecology research, microbes such as lactobacillus, bifidobacteria and bacteroides are mutually constrained and coordinated with the host and the environment to maintain the dynamic balance of the vaginal microecological system [14]. If the vaginal microecological flora loses this dynamic balance and the immune system is impaired, it is easier for foreign microorganisms to invade and cause inflammation within the reproductive tract [15]. The presence of inflammatory stimuli increases the risk of cancer [16]. Studies have shown that genital tract inflammation caused by HPV infection is closely related to tumorigenesis [17]. Studies have also found that the HPVpositive women have a greater diversity of vaginal microbial species than do HPV-negative women; in addition, the microbiome plays an important role in the development of cancer $[18,19]$. According to different studies, the vaginal microecology plays a crucial part in preventing HPV infection and accelerating HPV virus clearance and its homeostatic imbalance may be a synergistic factor for HPV infection $[20,21]$. The aim of this study was to analyze the relationship between the vaginal environment and HPV or $\mathrm{CIN}$ to provide some basis for regulating vaginal microecological balance, blocking HPV infection and intervening in the progression of cervical lesions.

\section{Materials and methods}

\section{Literature search}

Relevant studies on the association between vaginal microecology and HPV or CIN were identified through an extensive search of PubMed and Web of Science between January 2000 and December 2017 based on the following keywords: 'vaginal microecology','vaginal microenvironment', 'vaginal environment', 'vaginal microbiota', 'vaginal flora', 'cervicovaginal coinfections' or 'cervical inflammation', in combination with 'cervical intraepithelial neoplasia', 'cervical lesions', 'cervical dysplasia', 'human papillomavirus', 'papillomavirus infections' or 'HPV'. Studies were limited to those written in English. We performed a second search based on the references in the original literature.

\section{Research selection and data extraction}

Studies describing the relationship between vaginal microecology and CIN or HPV infection were included in this meta-analysis. Eligible studies were required to have clinical or pathological diagnostic information related to HPV and CIN. Articles were included if they presented data for calculation. Conference abstracts and other unpublished articles were excluded as these could not be systematically reviewed and the data could not be verified. Duplicate reports with similar content from the same author were excluded. Studies containing special occupational groups were excluded. The selected studies focused mainly on bacterial vaginosis (BV),Trichomonas vaginitis (TV), Chlamydia trachomatis (CT),Ureaplasma urealyticum (UU), lactobacillus, Candida albicans (VVC). The design and quality of all studies were evaluated using the NewcastleOttawa Scale (NOS) [22]. For each study, the following data were extracted: first author, year of publication, study type, type, number of case, number of control, risk factors and quality.

\section{Statistical analysis}

Data from each observation in the experimental and control groups were extracted. We used Review Manager 5.3 software to analyze the data and calculate the odds ratio (OR) and its 95\% confidence interval (95\% $\mathrm{CI})$. The results were visualized in a forest plot. Study homogeneity was quantified by $\mathrm{I}^{2}$ statistic test. The fixed effect model (Mantel and Haenszel method) was selected if the results showed $P>0.10$ and $\mathrm{I}^{2}<50 \%$; otherwise, the random effect model (DerSimonian and Laird method) was chosen. $P<0.05$ was considered to be statistically significant.

\section{Results}

We selected 13 studies from hundreds of articles based on established standards. These publications included nine studies on vaginal microecology and HPV infection, three studies on vaginal microecology and CIN and one study on vaginal microecology with HPV infection and CIN. A total of 5639 women were included in the in case group and 19,561 women in the control group.

\section{Vaginal microecology - cervical human papillomavirus association $B V$ with HPV infection}

Eight studies reported a comparison of BV detection rates in $\mathrm{HPV}$-positive and -negative individuals. Analysis of the association between BV and cervical HPV infection showed that HPV prevalence was higher in BV-positive women in seven out of eight studies compared with women without $\mathrm{BV}$. Among these women, the detection rate of BV in the HPV-positive group was $13.4 \%(624 / 4644)$, and that in the HPV-negative group was $6.6 \%(845 / 12752)$. The total results based on all eight studies (OR 2.62, 95\% CI 1.84-3.73, $P<$ 0.05 ) were statistically significant (Fig. 1), indicating a positive association between BV and cervical HPV infection.

\section{VVC with HPV infection}

Five studies analyzed the association between VVC and HPV infection. The detection rate of VVC in the HPVpositive group was $6.7 \%$ (93/1380), and that in the HPVnegative group was $4.1 \%(305 / 7480)$. A summary of all 


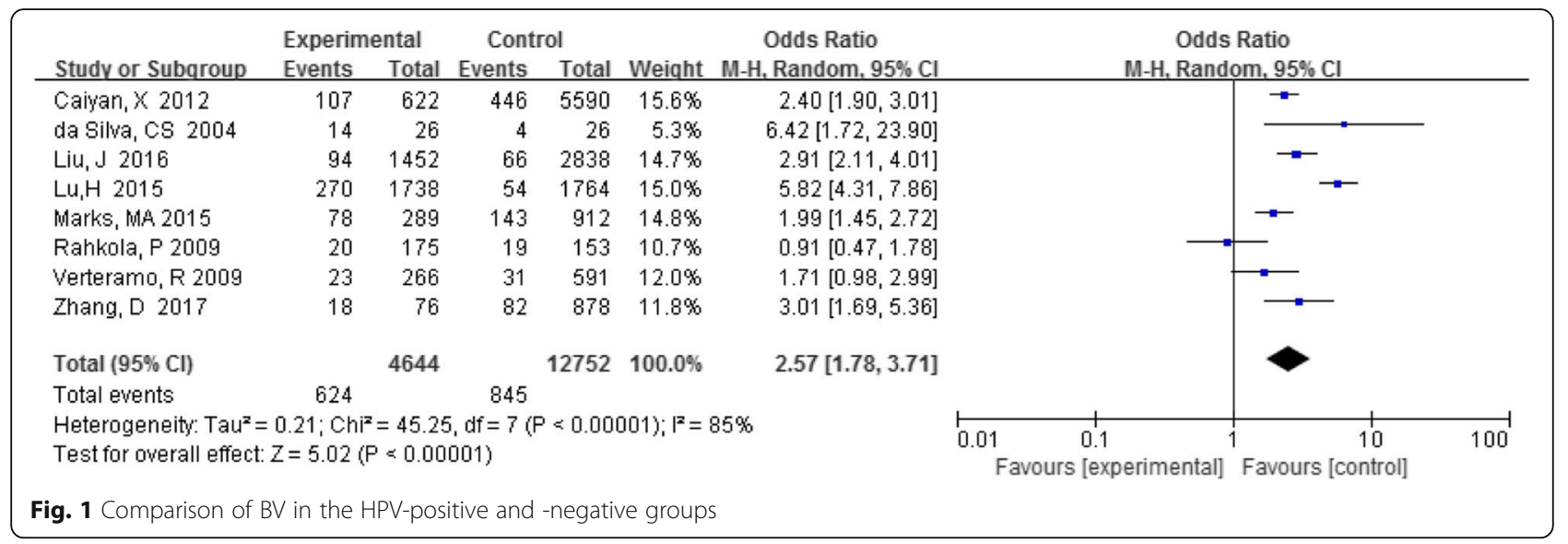

data showed that this association was statistically significant (OR 0.63, 95\%CI 0.49-0.82, $P<0.05$ )(Fig. 2).

\section{TV with HPV infection}

Five studies analyzed the association between TV and HPV infection, and individual studies showed no association between these infections. The detection rate of $\mathrm{TV}$ in the HPV-positive group was $2.7 \%$ (77/2806), and that in the HPV-negative group was 1.7\% (175/10293). A summary analysis of five studies showed that the OR of Trichomonas did not differ between the HPV-positive and -negative group (OR 1.19, 95\% CI 0.90-1.58, $P=0.22$ ) (Fig. 3).

\section{CT with HPV infection}

Five studies analyzed the association between CT and HPV infection. The detection rate of Chlamydia trachomatis was $5.9 \%(225 / 3821)$ in the HPV-positive group and $2.8 \%(196 / 6982)$ in the HPV-negative group. There was a statistically significant association when the results of all studies were analyzed together (OR 3.16, 95\% CI 2.55-3.90, $P<0.05$ ) (Fig. 4).

\section{UU with HPV infection}

Three articles analyzed the relationship between UU and HPV infection, and the results of the individual studies were different. There was a statistically significant association when the results of all studies were analyzed together (OR 1.35, 95\% CI 1.20-1.51, $P<$ 0.05) (Fig. 5). Lu, H [25] also reported that the detection rate of mycoplasma in the HPV-positive group (6.5\%) was significantly higher than the HPV-negative group $(1.2 \%)$.

\section{Lactobacillus with HPV infection}

The relationship between lactobacilli and HPV infection was studied by a single literature. Gao, W [24] reported that the detection rate of Lactobacillus in HPV-positive

Table 1 Characteristics of the selected studies included in the meta-analysis

\begin{tabular}{|c|c|c|c|c|c|c|c|}
\hline Authors & Year of publication & Study type & Type & Number of case & Number of control & risk factors & Quality \\
\hline da Silva et al. [23] & 2004 & Case-control & HPV & 26 & 26 & bh & 7 \\
\hline Gao et al. [24] & 2013 & Case-control & HPV & 32 & 38 & g & 7 \\
\hline Lu et al. [25] & 2015 & Case-control & HPV & 1738 & 1764 & $b d$ & 6 \\
\hline Caiyan et al. [26] & 2012 & Case-control & $\mathrm{CIN} / \mathrm{HPV}$ & $374 / 622$ & $5985 / 5590$ & bch & 7 \\
\hline Marks et al. [27] & 2015 & Case-control & HPV & 289 & 912 & $b d$ & 7 \\
\hline Behbakht et al. [28] & 2002 & Case-control & $\mathrm{CIN}$ & 17 & 34 & b & 6 \\
\hline Liu et al. [29] & 2016 & Case-control & HPV & 1452 & 2838 & bcde & 7 \\
\hline Murta et al. [30] & 2000 & Case-control & HPV & 390 & 396 & ch & 7 \\
\hline Rahkola et al. [31] & 2009 & Case-control & HPV & 175 & 153 & $b$ & 7 \\
\hline Zhang et al. [32] ${ }^{a}$ & 2017 & Case-control & HPV & 76 & 878 & bcdeh & 6 \\
\hline Schiff et al. [33] & 2000 & Case-control & $\mathrm{CIN}$ & 112 & 326 & bcd & 7 \\
\hline Verteramo et al. [34] & 2009 & Case-control & HPV & 266 & 591 & bcdeh & 7 \\
\hline Barcelos et al. [35] & 2011 & Case-control & $\mathrm{CIN}$ & 70 & 30 & bch & 7 \\
\hline
\end{tabular}

Note:b (BV), c (TV), d (CT), e (UU), g (Lactobacillus), h (VVC). ${ }^{a}$ a one participant in 954 women with the laboratory results of vaginal swab specimens missed the data of Candida, CT and UU 


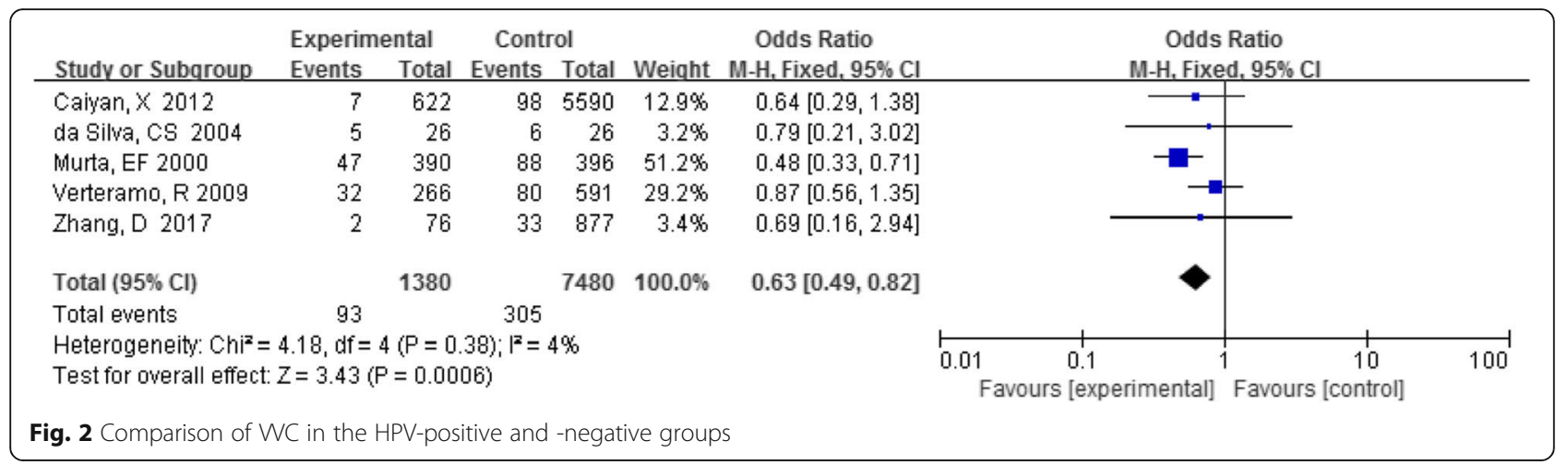

group (56.3\%) was lower than the HPV-negative group (60.5\%).

\section{Vaginal microecology - CIN association BV with CIN}

Four reports analyzed the correlation between BV and CIN, and the results of a single study were inconsistent. The detection rate of BV in the CIN group was 20.4\% (117/573), and in the control group it was $10.0 \%$ (636/6375). The summary results showed that the difference was statistically significant (OR 1.56, 95\% CI 1.21-2.00, $P<0.05$ ) (Fig. 6).

\section{TV with CIN}

Three papers researched the correlation between TV and CIN. All studies concluded that there was no significant correlation between TV and CIN. Among these studies, the detection rate of TV in the CIN group was $1.4 \%(8 / 556)$ and that in the control group was $0.9 \%(60 /$ 6341). As shown in Fig. 7, the summary results revealed that the difference was not statistically significant (OR $1.41,95 \%$ CI $0.62-3.24, P=0.41)$.

\section{VVC with CIN}

Two papers researched the correlation between Candida infection and CIN and reached the same conclusion that Candida infection has nothing to do with CIN. The detection rate of VVC in the CIN group was $4.1 \%(18 / 444)$, and that in the control group was $1.7 \%(104 / 6015)$. We combined the results to show that VVC and CIN were not significantly associated (OR 0.99, 95\% CI 0.50-1.98, $P=0.98$ ) (Fig. 8).

\section{Conclusions}

Cervical cancer is the most common malignant tumor in the female reproductive tract [36]. It is well known that infection with oncogenic HPV,especially HR-HPV,is the main etiological agent in the development of CIN and cervical cancer [37]. It is unknown why HR-HPV infection is cancerous in some women whereas in others it is eradicated. There may be individual differences in immunological defense, but local cervical factors may determine the outcome of HPV infection and CIN. With in-depth study of the human microecological system, the role of microecological balance in maintaining human health has been further emphasized [38]. Whether vaginal flora plays a role in persistent HPV infection and the development of CIN has been considered, as vaginal flora is an important factor in the stability of the vaginal environment. In this analysis, we included 13 studies and concluded that BV is associated with HPV infection and CIN, whereas CT and UU are associated with HPV infection.

$\mathrm{BV}$ is the most common vaginal infection in women of childbearing age. Previous systematic reviews [39] reported a positive association between BV and cervical HPV infection (OR 1.43, 95\% CI 1.11 1.84), which indicated that the presence of $\mathrm{BV}$ increases the risk of

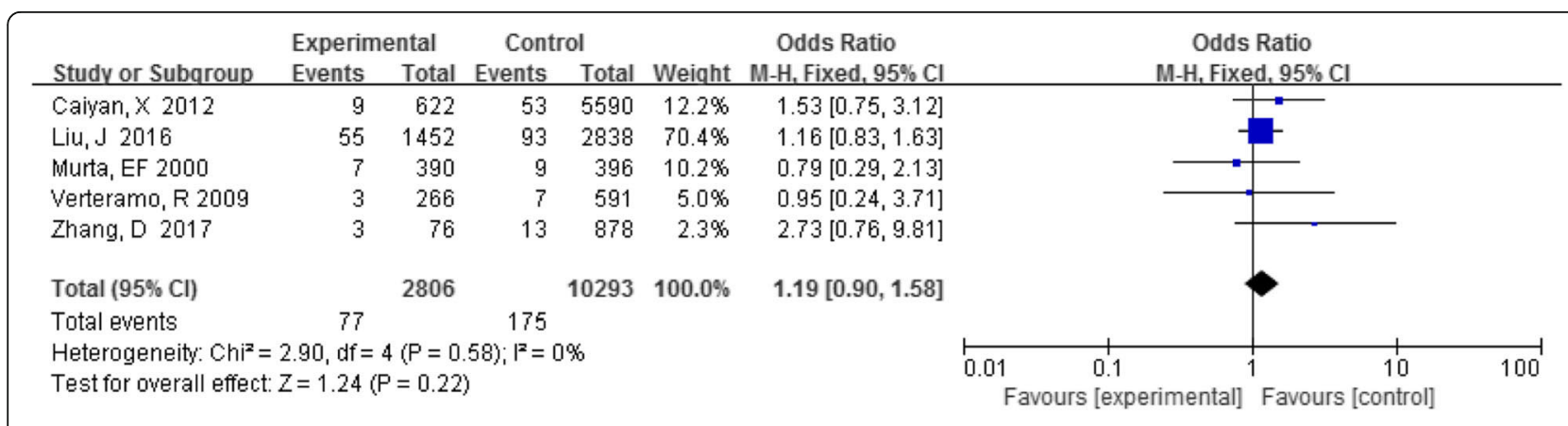

Fig. 3 Comparison of TV in the HPV-positive and -negative groups 


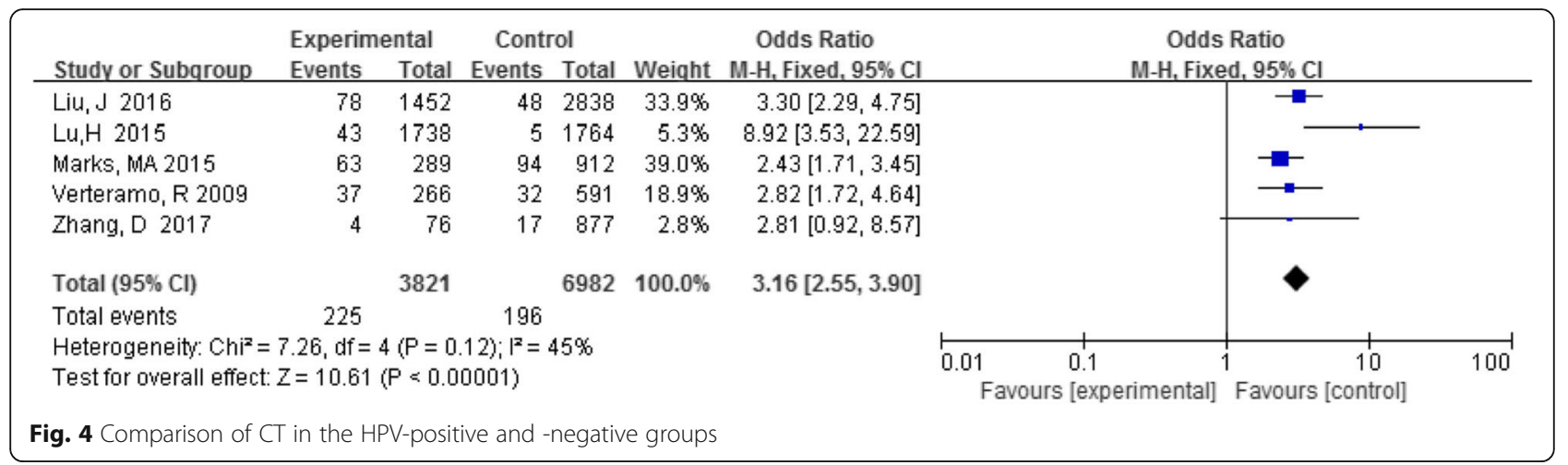

cervical HPV infection. The mechanism may be an increase in the mucin-degrading enzyme in the vaginal fluid of BV-positive patients, which can promote virulence by disrupting the protective mucosal barrier with the result of increasing the susceptibility to cervical HPV infection by promoting viral adhesion, invasion and eventual integration of HPV genome. It is also possible that the anaerobic bacterial metabolism of BV produces ammonia and carcinogenic ammonia nitrite in vaginal secretions, causing abnormal changes in cervical epithelial cells (such as cervical epithelial cell transformation, exfoliation). This study incorporated new publications to evaluate the relationship between BV and HPV infection, reaching a consistent conclusion that $\mathrm{BV}$ is associated with HPV infection. Furthermore, we also found that BV was associated with CIN (OR 1.56, 95\% CI 1.21-2.00, $P<0.05)$, therefore BV may increase the risk of cervical HPV infection and CIN development. Sodhani P et al. [40] found that precancerous lesions were more frequently detected in smears of bacterial vaginosis from a total of 24,565 smears $(P<0.0001)$. Meanwhile, Zhang, $\mathrm{H}$ et al. [41] reported the cervical microbial diversity was reduced in CIN II/III patients after the loop electrosurgical excision procedure (LEEP). However, we have not been able to prove that curing $\mathrm{BV}$ is conducive to the clearance of HPV and the outcome of CIN from this study, and further research is needed.

TV and VVC infections are common genital tract infections in women. Candida albicans is an opportunistic pathogen that usually does not cause disease on the vaginal mucosa but may cause disease when the body's immunity is reduced or the vaginal acidic environment changes [42]. TV is a contagious parasitic disease mainly transmitted through sexual intercourse [43]. Whether the natural history of HPV infection is affected by VVC or TV infection has not been fully investigated. In this meta-analysis, Caiyan, $\mathrm{X}$ et al. [26] concluded that TV infection was not associated with HPV and CIN. However, according to recent reports, Feng RM et al. [44] analyzed 25,054 women in rural China using liquid-based cytology and found that HPV was more prevalent in TVpositive women (OR 1.31, 95\% CI: 1.11-1.56). However, TV-positive women had a reduced risk of CIN2+, especially among women with HR-HPV infection. Regarding the relationship between $\mathrm{VVC}$ and HPV infection or CIN, this meta-analysis found that there was no significant correlation between TV and HPV infection and CIN $(P>0.05)$, and that VVC is a protective factor for $\mathrm{HPV}$ infection (OR $0.63,95 \% \mathrm{CI}$ $0.49-0.82, P<0.05)$ and had no correlation with $\mathrm{CIN}(P>0.05)$. Meanwhile, Engberts $\mathrm{MK}$ et al. [45] also concluded that Candida did not increase the risk of developing cervical cancer, and it was reported that Candida could be used as a new adjuvant for HPV therapeutic vaccines as it could enhance the immune response by enhancing $\mathrm{T}$ cell proliferation [46]. Based on these results, further research should be conducted

\begin{tabular}{|c|c|c|c|c|c|c|c|c|c|c|}
\hline Study or Subqroup & \multicolumn{2}{|c|}{ Experimental } & \multicolumn{2}{|c|}{ Control } & Weiaht & $\begin{array}{c}\text { Odds Ratio } \\
\text { M-H. Fixed. } 95 \% \text { C }\end{array}$ & \multicolumn{4}{|c|}{$\begin{array}{c}\text { Odds Ratio } \\
\text { M-H, Fixed, } 95 \% \mathrm{Cl}\end{array}$} \\
\hline Lim, J J 2016 & 845 & 1452 & 1460 & 2838 & $82.3 \%$ & $1.31[1.16,1.49]$ & & & & \\
\hline Verteramo, R 2009 & 96 & 266 & 147 & 591 & $11.6 \%$ & $1.71[1.25,2.33]$ & & & $\rightarrow$ & \\
\hline Zhang, D 2017 & 29 & 76 & 309 & 877 & $6.1 \%$ & $1.13[0.70,1.84]$ & & & 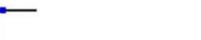 & \\
\hline Total $(95 \% \mathrm{Cl})$ & & 1794 & & 4306 & $100.0 \%$ & $1.35[1.20,1.51]$ & & & 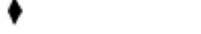 & \\
\hline Total events & 970 & & 1916 & & & & & & & \\
\hline $\begin{array}{l}\text { Heterogeneity: Chi }{ }^{2}= \\
\text { Test for overall effect }\end{array}$ & $\begin{array}{l}2.83, \mathrm{df}= \\
Z=5.11\end{array}$ & $\begin{array}{l}(P=0 . \\
=0.00\end{array}$ & $\begin{array}{l}\text { 24); }\left.\right|^{2}=2 \\
001)\end{array}$ & $29 \%$ & & & ${ }^{0.01} \mathrm{~F}$ & $\begin{array}{l}0.1 \\
\text { s [experimental] }\end{array}$ & $\begin{array}{c}10 \\
\text { Favours [control] }\end{array}$ & $100^{\circ}$ \\
\hline
\end{tabular}




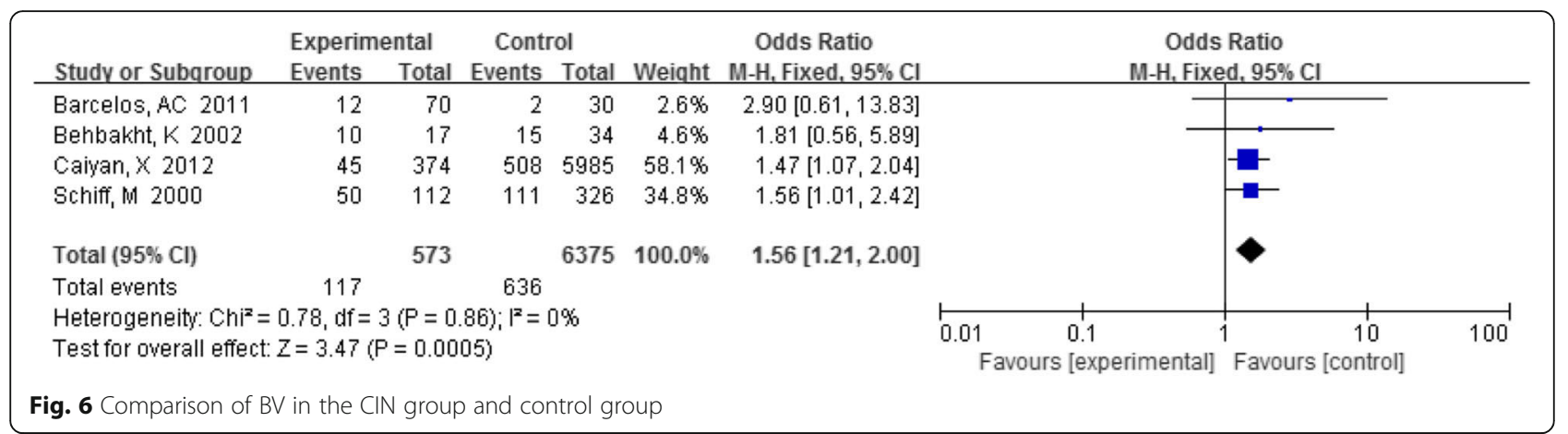

to assess the relationship and mechanism between TV or VVC and HPV or CIN to increase patient benefit.

In recent years, reports on the relationship between mycoplasma and chlamydia infection and HPV infection and cervical lesions have gradually increased [47]. Whether mycoplasma and chlamydia infection are synergistic factors in the development of cervical cancer is still controversial in current research. This study found that the detection rate of CT in HPV positive group was 5.9\% (225/3821), UU was $5.4 \%$ (970/1794), and the detection rate of CT in HPV negative group was 2.8\% (196/6982),UU was 4.5\% (1916/ 4305). The differences were statistically significant (OR $3.16,95 \%$ CI $2.55-3.90, P<0.05$; OR 1.35 , 95\% CI 1.20 $1.51, P<0.05)$. This indicating that both UU and CT increased the risk of HPV infection; the risk of HPV infection increased by 1.35 -times in UU-positive patients and by 3.16-times in CT-positive patients. Different studies have reported that UU plays an important role in initiating abnormalities and persistence of viral cells, and it is a cofactor for HPV to promote precancerous lesions that lead to cervical cancer $[48,49]$. The possible mechanism of the association between UU infection and abnormal cervical cytopathology might be related to the combination of several complex infection-associated infammatory responses [50], involving production of reactive oxidative metabolites, increased expression of cytokines, chemokines,and growth and angiogenic factors, decreased cell-mediated immunity, and the generation of free radicals [51]. Valadan $\mathrm{M}$ et al. [52] also found a significant association between CT infection and $\mathrm{CIN}$ in a case-control study $(\mathrm{OR}=5.5,95 \% \mathrm{CI}$
2.4-12.4). The possible mechanism for this association is that chlamydia adsorbs to the genital mucosa after infection, causing damage and inflammatory reactions in genital mucosal epithelial cells, reducing cervical and vaginal immune barriers, and facilitating HPV infection to trigger $\mathrm{CIN}$ and cervical cancer [34]. In this meta-analysis, CT and UU were positively associated with HPV infection. However, larger samples and long-term follow-up studies are necessary to further confirm these results.

The changes in vaginal $\mathrm{pH}$ may play a major role during the progression of HPV infection and CIN to cervical cancer. Under normal circumstances, Lactobacillus is the most dominant bacterial genus in the female vagina, and it can regulate the structure of vaginal flora and maintain the stability of vaginal microenvironment by producing a variety of bacteriostatic and bacteriocidal metabolites, such as lactic acid, $\mathrm{H}_{2} \mathrm{O}_{2}$, and biosurfactants bacteriocin [13]. HPV infection results in the loss of local lactic acid bacteria, destroying the biological barrier of the local vaginal immune microenvironment, aggravating the destruction of the vaginal environment, promoting the abnormal adhesion of HPV in the vagina, causing a local microecological imbalance in the vagina and destroying the local immune function of the cervix while simultaneously increasing the adhesion, invasion and colonization of abnormal flora [53]. This will form a vicious cycle in the vaginal environment, resulting in the further development of HPV infection, thereby inducing cervical lesions. Clarke MA et a1 [54]. conducted a study of the relationship between vaginal $\mathrm{pH}$ and HPV

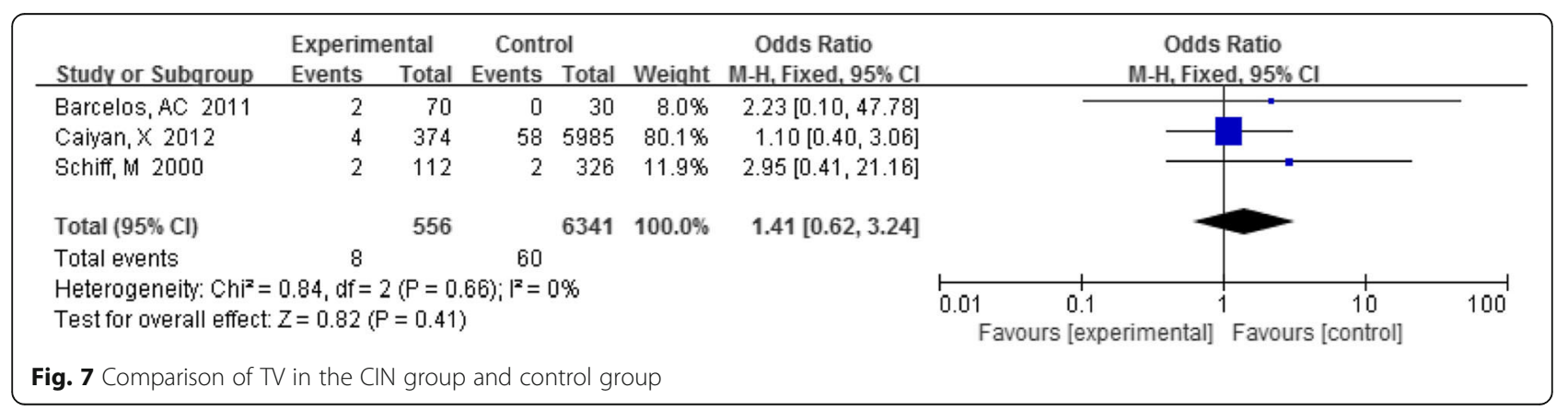




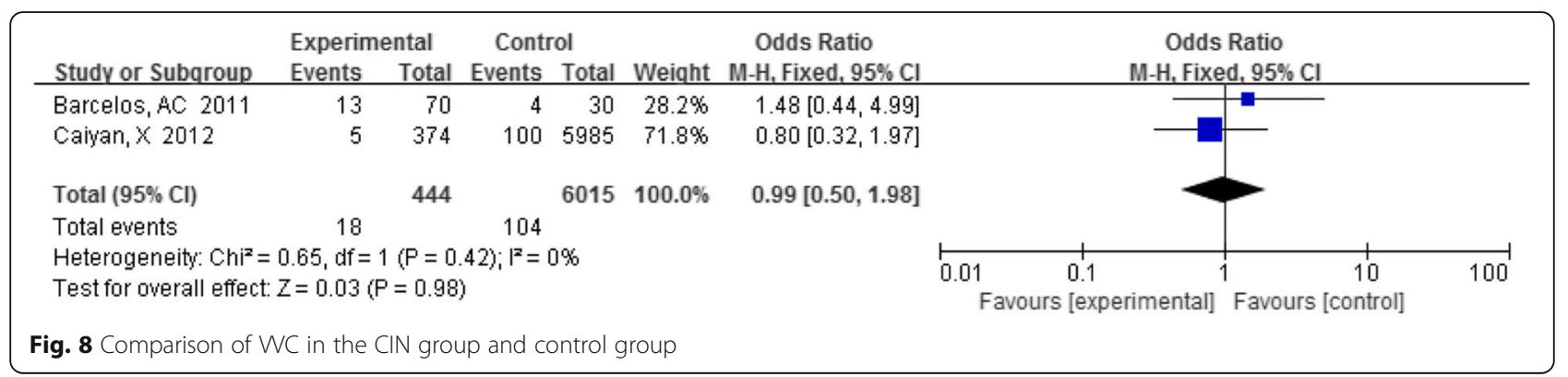

infection in 9165 women and showed that vaginal $\mathrm{pH}$ was closely related to HPV infection, especially in women under 35 years of age. In addition, increased vaginal $\mathrm{pH}$ in women $<35$ years old and $>65$ years old increased the risk of multiple HPV infections, indicating the importance of vaginal $\mathrm{pH}$ in maintaining the balance of the vaginal environment. In this study, only a single article [24] reported the relationship between HPV infection and Lactobacillus, and the detection rate of Lactobacillus in the HPV-positive group (56.3\%) was lower than that in the HPV-negative group (60.5\%). Therefore, a large number of samples is needed to verify the relationship between vaginal $\mathrm{pH}$ imbalance caused by lactobacillus changes and the development of HPV infection and cervical cancer.

To conclude, this meta-analysis indicated that BV, UU, CT and reduction of Lactobacilli are associated to increase risk of HPV infection and CIN development, while TV and Candida albicans infections are not significantly associated to HPV infection and CIN development and may have a protective effect. In short, the female genital tract system is a complex microbial environment, and avoiding a vaginal flora imbalance may have a significant effect on preventing HPV infection and CIN development. This metaanalysis suggests an intimate connection between vaginal microecology and HPV infection or CIN. Considering that these conditions are very common among women worldwide, further research in this field is imperative.

This meta-analysis was limited to that of published studies, which could have caused publication bias, resulting from tendency to selectively publish results that are statistically significant. Additionally, the lack of some literature data may lead to a bias in results. Therefore, more rigorous controlled studies with increased sample sizes are required to provide a more reliable experimental basis.

\section{Authors' contributions}

YJL and HW Project development, data collection, manuscript writing/ editing. LQ contributed analysis tools. MJC revised the manuscript. BW data collection. All authors read and approved the final manuscript.

\section{Funding}

This work was supported by grants from Open Project of Key Laboratory of Guangxi Science and Technology Department (No:GKK201613), Special fund for the key laboratory for early prevention and treatment of regional highincidence tumors in Guangxi (No:GK2015-ZZ09), and Guangxi's 18th batch of "New Century Ten Thousand Talents Project" second-level candidate special fund.

Availability of data and materials

All data generated or analyzed during this study are included in this published article.

Ethics approval and consent to participate

Not applicable.

\section{Consent for publication}

Informed consent Informed consent was obtained from all individual participants included in the study.

\section{Competing interests}

The authors declare that they have no competing interests.

Received: 18 April 2019 Accepted: 5 September 2019

Published online: 26 October 2019

\section{References}

1. Thun MJ, DeLancey JO, Center MM, et al. The global burden of cancer: priorities for prevention [J]. Carcinogenesis. 2010;31(1):100-10.

2. Wright TC, Cox JT, Massad LS. 2001 consensus guidelines for the management of women with cervical intraepithelial neoplasia [J]. Am J Obstet Gynecol. 2003;189(1):295-304.

3. He ZH, Kou ZQ, Xu AQ. HPV infection and its immune prevention [J]. Chin J Prev Med. 2018;52(1):106-12.

4. Moscicki AB, Ma Y, Wibbelsman $C$, et al. Rate of and risks for regression of cervical intraepithelial neoplasia 2 in adolescents and young women [J]. Obstet Gynecol. 2010;116(6):1373-80.

5. Sun JH, Cai SM, Gao YL. Gynecologic oncology [M]. Peking Univ Med Press. 2011;27(1):491-3.

6. Richardson $H$, Kelsall $G$, Tellier $P$, et al. The natural history of type-specific human papillomavirus infections in female university students [J]. Cancer Epidemiol Biomark Prev. 2003;12(6):485-90.

7. Gravitt PE. The known unknowns of HPV natural history [J]. J Clin Invest. 2011;121(12):4593-9.

8. Snijders PJ, van den Brule AJ, Meijer CJ. The clinical relevance of human papillomavirus testing: relationship between analytical and clinical sensitivity [J]. J Pathol. 2003;201(1):1-6.

9. Meijer CJ, Walboomers JM. Cervical cytology after 2000: where to go? [J]. J Clin Pathol. 2000;53(1):41-3.

10. Kyrgiou M, Mitra A, Moscicki AB. Does the vaginal microbiota play a role in the development of cervical cancer?[J]. Transl Res. 2017;179:168-82.

11. Jiang YM, Li L. Prediction of the Progress of cervical intraepithelial neoplasia [J]. J Int Obstet Gynecol. 2018:45(01):71-5.

12. Mitra A, Maclntyre DA, Marchesi JR, et al. The vaginal microbiota, human papillomavirus infection and cervical intraepithelial neoplasia: what do we know and where are we going next?[J]. Microbiome. 2016;4(1):58. 
13. Liao QP. Female vaginal microecology and vaginal microecology evaluation [J]. Pract J Obstet Gynecol. 2010;26(2):81-3.

14. Chinese Medical Association Obstetrics and Gynecology Branch Infectious Diseases Cooperative Group. Expert consensus on clinical application of vaginal microecology evaluation [J]. Chin J Obstet Gynecol. 2016;51(10):721-3.

15. Chehoud C, Stieh DJ, Bailey AG, et al. Associations of the vaginal microbiota with HIV infection, bacterial vaginosis, and demographic factors [J]. AIDS. 2017;31(7):895-904.

16. Balkwill F, Mantovani A. Inflammation and cancer: back to Virchow?[J]. Lancet. 2001:357:539-45.

17. Jin J. HPV infection and Cancer [J]. JAMA. 2018;319(10):1058.

18. Di Paola M, Sani C, Clemente AM, et al. Characterization of cervico-vaginal microbiota in women developing persistent high-risk Human Papillomavirus infection [J]. Sci Rep. 2017;7(1):10200.

19. Champer M, Wong AM, Champer J, et al. The role of the vaginal microbiome in gynaecological cancer [J]. BJOG. 2018;125(3):309-15.

20. Lee JE, Lee $S$, Lee $H$, et al. Association of the Vaginal Microbiota with Human Papillomavirus Infection in a Korean Twin Cohort [J]. PLoS One. 2013;8(5):e63514.

21. Parkin DM, Hämmerl L, Ferlay J, et al. Cancer in Africa 2018: the role of infections [J]. Int J Cancer. 2019.

22. Stang A. Critical evaluation of the Newcastle-Ottawa scale for the assessment of the quality of nonrandomized studies in meta-analyses [J]. Eur J Epidemiol. 2010;25(9):603-5.

23. da Silva CS, Adad SJ, Hazarabedian de Souza MA, et al. Increased frequency of bacterial vaginosis and chlamydia trachomatis in pregnant women with human papillomavirus infection [J]. Gynecol Obstet Investig. 2004;58(4):189-93.

24. Gao W, Weng J, Gao Y, et al. Comparison of the vaginal microbiota diversity of women with and without human papillomavirus infection: a crosssectional study [J]. BMC Infect Dis. 2013;13:271.

25. Lu H, Jiang $P C$, Zhang XD, et al. Characteristics of bacterial vaginosis infection in cervical lesions with high risk human papillomavirus infection [J]. Int J Clin Exp Med. 2015;8(11):21080-8.

26. Caiyan $X$, Weiyuan Z, Minghui $W$, et al. Prevalence and risk factors of lower genital tract infections among women in Beijing, China [J]. J Obstet Gynaecol Res. 2012;38(1):310-5.

27. Marks MA, Gupta S, Liaw KL, et al. Prevalence and correlates of HPV among women attending family-planning clinics in Thailand [J]. BMC Infect Dis. 2015;15:159.

28. Behbakht K, Friedman J, Heimler I, et al. Role of the vaginal microbiological ecosystem and cytokine profile in the promotion of cervical dysplasia: a case-control study [J]. Infect Dis Obstet Gynecol. 2002;10(4):181-6.

29. Liu J, Liu W, Liu Y, et al. Prevalence of microorganisms co-infections in human papillomaviruses infected women in northern China [J]. Arch Gynecol Obstet. 2016;293(3):595-602.

30. Murta EF, Souza MA, Araujo Junior E, et al. Incidence of Gardnerella vaginalis, Candida sp and human papilloma virus in cytological smears [J]. Sao Paulo Med J. 2000;118(4):105-8.

31. Rahkola P, Mikkola TS, Ylikorkala O, et al. Association between high risk papillomavirus DNA and nitric oxide release in the human uterine cervix [J]. Gynecol Oncol. 2009;114(2):323-6.

32. Zhang D, Li T, Chen L, et al. Epidemiological investigation of the relationship between common lower genital tract infections and high-risk human papillomavirus infections among women in Beijing, China [J]. PLoS One. 2017;12(5):e0178033.

33. Schiff M, Becker TM, Masuk M, et al. Risk factors for cervical intraepithelial neoplasia in southwestern American Indian women [J]. Am J Epidemiol. 2000;152(8):716-26.

34. Verteramo R, Pierangeli A, Mancini E, et al. Human papillomaviruses and genital co-infections in gynaecological outpatients [J]. BMC Infect Dis. 2009;9:16

35. Barcelos AC, Michelin MA, Adad SJ, et al. Atypical squamous cells of undetermined significance: Bethesda classification and association with Human Papillomavirus [J]. Infect Dis Obstet Gynecol. 2011;2011:904674.

36. Parkin DM. Global cancer statistics in the year 2000 [J]. Lancet Oncol. 2001;2(9):533-43

37. Koshiol J, Lindsay L, Pimenta JM, et al. Persistent human papillomavirus infection and cervical neoplasia: a systematic review and meta-analysis [J]. Am J Epidemiol. 2008;168(2):123-37.

38. Shen X, Yao YF, Li JY, et al. Human mycobiome and diseases [J]. West China J Stomatol. 2019;37(3):314-9.
39. Gillet $E$, Meys JF, Verstraelen $H$, et al. Bacterial vaginosis is associated with uterine cervical human papillomavirus infection: a meta-analysis [J]. BMC Infect Dis. 2011;11:10.

40. Sodhani P, Gupta S, Gupta R, et al. Bacterial vaginosis and cervical intraepithelial neoplasia: is there an association or is co-existence incidental?[J]. Asian Pac J Cancer Prev. 2017;18(5):1289-92.

41. Zhang H, Lu J, Lu Y, et al. Cervical microbiome is altered in cervical intraepithelial neoplasia after loop electrosurgical excision procedure in china [J]. Sci Rep. 2018;8(1):4923.

42. Donders Gilbert GG, Prenen H, Verbeke G, et al. Impaired tolerance for glucose in women with recurrent vaginal candidiasis [J]. Am J Obstet Gynecol. 2002;187:989-93.

43. Donders Gilbert GG, Ruban K, Depuydt C, et al. Treatment attitudes for Belgian women with persistent trichomonas vaginalis infection in the VlaResT study [J]. Clin Infect Dis. 2019;68:1575-80.

44. Feng RM, Z Wang M, Smith JS, et al. Risk of high-risk human papillomavirus infection and cervical precancerous lesions with past or current trichomonas infection: a pooled analysis of 25,054 women in rural China [J]. J Clin Virol. 2018;99-100:84-90.

45. Engberts MK, Vermeulen CF, Verbruggen BS, et al. Candida and squamous (pre) neoplasia of immigrants and Dutch women as established in populationbased cervical screening [J]. Int J Gynecol Cancer. 2006;16(4):1596-600.

46. Wang $X$, Coleman HN, Nagarajan U, et al. Candida skin test reagent as a novel adjuvant for a human papillomavirus peptide-based therapeutic vaccine [J]. Vaccine. 2013;31(49):5806-13.

47. Zhang LD, Pei J, Zhang HM, et al. Relationship between mycoplasma and chlamydia infection and lesions in the cervical tissue in high-risk HPV-positive patients [J]. Zhonghua Shi Yan He Lin Chuang Bing Du Xue Za Zhi. 2010;24:346-8.

48. Lukic A, Canzio C, Patella A, et al. Determination of cervicovaginal microorganisms in women with abnormal cervical cytology: the role of Ureaplasma urealyticum [J]. Anticancer Res. 2006;26(6C):4843-9.

49. Biernat-Sudolska M, Szostek S, Rojek-Zakrzewska D, et al. Concomitant infections with human papillomavirus and various mycoplasma and ureaplasma species in women with abnormal cervical cytology.[J]. Adv Med Sci. 2011;56:299-303.

50. Mariana MC, Adriana CP, Alma CB, et al. Prevalence of sexually transmitted pathogens associated with HPV infection in cervical samples in a Mexican population [J]. J Med Virol. 2015;87(12):2098-2105.

51. Castle PE, Giuliano AR. Genital tract infections,cervical infammation, and antioxidant nutrients-assessing their roles as human papillomavirus cofactors [J]. J Natl Cancer Inst Monogr. 2003;31:29-34.

52. Valadan M, Yarandi F, Eftekhar Z, et al. Chlamydia trachomatis and cervical intraepithelial neoplasia in married women in a Middle Eastern community [J]. East Mediterr Health J. 2010;16(3):304-7.

53. Golijow CD, Abba MC, Mourón SA, et al. Chlamydia trachomatis and human apillomavirus infections in cervical disease in argentine women [J]. Gynecol Oncol. 2005:96(1):181-6.

54. Clarke MA, Rodriguez AC, Gage JC. A large, population-based study of agerelated associations between vaginal ph and human papillomavirus infection [J]. BMC Infect Dis. 2012;12(1):33.

\section{Publisher's Note}

Springer Nature remains neutral with regard to jurisdictional claims in published maps and institutional affiliations.

\section{Ready to submit your research? Choose BMC and benefit from:}

- fast, convenient online submission

- thorough peer review by experienced researchers in your field

- rapid publication on acceptance

- support for research data, including large and complex data types

- gold Open Access which fosters wider collaboration and increased citations

- maximum visibility for your research: over $100 \mathrm{M}$ website views per year

At $\mathrm{BMC}$, research is always in progress.

Learn more biomedcentral.com/submission 